Esta revista forma parte del acervo de la Biblioteca Jurídica Virtual del Instituto de Investigaciones Jurídicas de la UNAM

\title{
Repúblicas bolivarianas e o ICSID: será que o inimigo não é outro?
}

\author{
Bolivarian Republics and ICSID: \\ Who is the Real Enemy?
}

Daniel TAVELA Luís*

José Augusto FonTOURA COSTA**

\begin{abstract}
SUMÁRIO: I. Introdução. II. Observações técnicas a respeito do sistema internacional de promoção e proteção do investimento estrangeiro. III. A perspectiva das repúblicas bolivarianas: saindo do sistema internacional de proteção de investimentos? IV. Alternativas ao ICSID para as repúblicas bolivarianas. V. Conclusão: rumos efetivos para a América Latina?. VI. Referências bibliográficas.
\end{abstract}

* Advogado em São Paulo. Doutorando em Direito Internacional da Faculdade de Direito da USP. Coach da FGV Direito SP (Willem C. Vis Int. Com. Arb. Moot).

** Professor da Faculdade de Direito de São Paulo (USP). Pesquisador com bolsa de produtividade do Conselho Nacional de Pesquisa Científica (CNPq).

Artículo recibido el 5 de marzo de 2015 Aprobado para publicación el 31 de agosto de 2015 
ABSTRACT: Latin American countries, mainly the so called Bolivarian Republics, lead a reaction against the international system of promotion and protection of foreign investments. Their reaction's focus is the ICSID, which is regarded as a non-democratic and pro-investor institution that issues awards against developing and peripheral states. This article puts that political perception in perspective through the analisys of the lagal structure of the international tandem between ICSID and investment treaties, and the effective arbitration cases against Bolivia, Ecuador and Venezuela, as well as a brief study on regional alternatives and constitutional constraints.

Key words: ICSID, investment arbitration, treaty arbitration, Bolivarian Republics, foreign investment, international investment protection.

ResUmO: Países latino-americanos, principalmente as chamadas Repúblicas Bolivarianas, lideram uma reação contra o sistema internacional de promoção e proteção dos investimentos estrangeiros. Sua reação se concentra no ICSID, visto como uma instituição antidemocrática e pró-investidores que prolata laudos contrários a países em desenvolvimento e periféricos. Este artigo coloca tal percepção em perspectiva mediante a análise da estrutura jurídica e do conjunto formado pelo ICSID e os tratados sobre investimento, assim como dos efetivos casos arbitrais contra Bolívia, Equador e Venezuela. Realiza-se, ainda, um breve estudo das alternativas regionais e das restrições constitucionais.

Palavras-chave: ICSID, arbitragem de investimento, arbitragem com base em tratado, republicas bolivarianas, investimento estrangeiro, proteção internacional do investimento.

RÉSUMÉ: Pays d'Amérique latine, en particulier les républiques dites bolivariens, entraînant une réaction contre le système international pour la promotion et la protection des investissements étrangers. Sa réaction est concentrée dans le CIRDI, considéré comme une institution non démocratique et pro- investisseurs, dont les rapports allongé contrairement aux pays en développement et les périphériques. Cet article met cette perception en perspective en analysant le cadre juridique et d'une combinaison de CIRDI et d'investissement traités, ainsi que les cas réels d'arbitrage contre la Bolivie, l'Équateur et le Venezuela . A lieu, encore, une brève étude des alternatives régionales et des restrictions constitutionnelles.

Mots-clés: Arbitrage d'investissement, CIRDI, l'arbitrage basé sur traité, républiques bolivariens, les investissements étrangers, la protection internationale de l'investissement. 


\section{INTRODUÇÃO}

A América Latina vem liderando a reação contra o sistema internacional de proteção e promoção do investimento estrangeiro, o qual se apoia, principalmente, em tratados internacionais específicos e na arbitragem do Centro Internacional para Solução de Controvérsias sobre Investimentos (ICSID). ${ }^{1}$ Os motivos para esta reação forte da região contra o ICSID são variados, mas podem ser resumidos a duas percepções centrais: (i) a existência de um viés pró-investidor, e; (ii) o risco a políticas públicas soberanas legítimas, em especial nas áreas ambiental, de saúde, trabalho e direitos indígenas.

Este cenário explicaria, segundo alguns autores: (i) a recusa do Brasil a ratificar a Convenção de Washington, por razões supostamente políticas e econômicas; (ii) a denúncia da Convenção de Washington por parte de Bolívia, Equador e Venezuela; (iii) a ameaça de denúncia da Convenção de Washington por parte da Argentina, e; (iv) as discussões no âmbito da UNASUL para criação de um centro de solução de disputas similar ao ICSID, mas de âmbito regional. ${ }^{2}$

Diante deste cenário, este artigo tem por objetivo entender a estratégia das repúblicas bolivarianas da Bolívia, Equador e Venezuela ao denunciar a Convenção de Washington e propor uma breve reflexão sobre os caminhos que existem para a América Latina ao se tratar do sistema internacional de proteção ao investimento.

Embora seja possível relacionar diversas variáveis a tal estratégia, o presente artigo avalia a influência de três fatores: (i) os casos de arbitragem de investimento envolvendo esses Estados, no ICSID e em outros foros, e seus resultados já disponíveis, (ii) a opção por abandonar a Convenção de Washington de 1965 associada, ou não, à denúncia de acordos internacionais

\footnotetext{
1 Waibel, Michael et al., The Backlash Against Investment Arbitration: Perceptions and Reality, Kluwer Law International, 2010.

2 Dalmaso, Ricardo, Notes on the Persitent Latin American Countries' Attitude Towards Investment Arbitration and ICSID. Disponível em http://kluwerarbitrationblog.com/ blog/2014/07/24/some-notes-on-the-latin-american-countries-attitude-towards-investment-arbitration-and-icsid/ (ultimo acesso em: 20 de fevereiro de 2015).
} 
Esta revista forma parte del acervo de la Biblioteca Jurídica Virtual del Instituto de Investigaciones Jurídicas de la UNAM

de investimento e (iii) as normas constitucionais restritivas da submissão à arbitragem de investimento.

Disso resultam três hipóteses que, se confirmadas, corroboram a relação entre os motivos contrários à arbitragem já apontados (viés e restrição de políticas) e as estratégias adotadas: (i) os casos de que os países participaram confirmam a percepção de haver viés arbitral contra os Estados; (ii) há saída do ICSID, mas não se questionam os acordos internacionais de investimento e (iii) as normas constitucionais são mais um ponto de apoio retórico do que uma exigência vigorosa da Ordem jurídica.

Para abordar a reação latino-americana contra o sistema internacional de proteção e promoção dos investimentos estrangeiros em sua composição atual, o presente artigo realiza uma breve revisão técnica das características dos acordos sobre investimento e das arbitragens do ICSID. Em seguida, analisa e avalia a perspectiva das repúblicas bolivarianas com a finalidade de gerar uma compreensão analítica do fenômeno e realizar uma crítica ao discurso legitimador normalmente empregado.

\section{OBSERVAÇÕES TÉCNICAS A RESPEITO DO SISTEMA INTERNACIONAL DE PROMOÇÃO E PROTEÇÃO DO INVESTIMENTO ESTRANGEIRO}

Pode-se dizer que a pedra angular do chamado sistema internacional de proteção ao investimento estrangeiro é a Convenção de Washington de 1965, que criou e estabeleceu, no âmbito do Banco Mundial, o Centro Internacional para Solução de Disputas relacionadas ao Investimento (ICSID). A função primordial do ICSID neste sistema é a de administrar procedimentos arbitrais e de conciliação sob sua jurisdição. ${ }^{3}$ Em outras palavras, o ICSID tem uma função fundamentalmente procedimental neste sistema, sem qualquer influência sobre a natureza e o conteúdo de regras substantivas.

As questões materiais de proteção do investimento, que dizem respeito aos direitos e deveres dos investidores e dos Estados podem ter diferentes

3 Como qualquer outra câmara arbitral, a administração do procedimento arbitral inclui tarefas importantes como, por exemplo, a indicação do presidente do tribunal arbitral, caso as partes não cheguem a um consenso, a análise prima facie da jurisdição do centro para receber determinada controvérsia, a cobrança de taxas de administração e honorários de árbitros, entre tantas outras. 
origens formais, como Direito internacional geral, contratos e legislação interna. Destacam-se, no sistema internacional atual, os acordos de promoção e proteção recíproca de investimentos (APPRIs), os quais estabelecem obrigações específicas (p. ex. cobertura das expropriações regulatórias e padrões de indenização), padrões de tratamento (proteção integral, tratamento justo e equitativo, tratamento nacional e cláusula de nação mais favorecida) e sistemas de solução de controvérsia entre os Estados partes e entre investidores e Estados, muitas vezes oferecendo o consentimento para arbitragens ICSID.

Em termos técnicos, portanto, a jurisdição dos tribunais arbitrais do ICSID tem seu fundamento na Convenção de Washington de 1965, entretanto nenhuma arbitragem pode ocorrer sem o consentimento por escrito de ambas as partes na controvérsia (Artigo 25). A maior parte das arbitragens mistas de investimento deriva de consentimento dado pelo Estado em APPRIs e pelo investidor mediante o próprio pedido de instauração da arbitragem; o Direito aplicável nesses pleitos, portanto, é o estabelecido e delimitado nestes mesmos acordos (às vezes com referências ao Direito interno do Estado receptor do investimento e/ou ao Direito internacional geral).

Portanto, embora o ICSID seja um instrumento independente dos APPRIs, tanto histórica ${ }^{4}$ quanto tecnicamente, o grande incremento das arbitragens a partir dos anos 1990 projeta a percepção de um amálgama indestrutível. Discursos políticos não se constróem sobre a base de conceitos jurídicos sofisticados, mas na maniqueização do mundo e, portanto, colocando no mesmo saco o Banco Mundial, os árbitros internacionais e, claro, os oposicionistas. Nada de excepcional, mas é importante observar que o instituto da arbitragem dos investimentos sofre ataques que seriam melhor direcionados aos APPRIs ou, por vezes, a problemas internos de gestão governamental.

Ocorre, também, que a estrutura jurídica predominante de proteção internacional de investimentos dispõe de uma toponomia curiosa: regras materiais e instrumentos processuais encontram-se em tratados diversos e, portanto, submetidos a dinâmicas de vigor e denúncia diferenciados. Deste modo, a saída do ICSID pode se apresentar como uma alternativa politicamente aceitável de extrair os dentes aos APPRIs sem ter de aguardar dez

4 Parra, Antonio R., The history of ICSID, Oxford, Oxford University Press, 2012. 
Esta revista forma parte del acervo de la Biblioteca Jurídica Virtual del Instituto de Investigaciones Jurídicas de la UNAM www.juridicas.unam. $\mathrm{mx}$

ou mais anos pelo fim de seus efeitos, como tantas vezes aparece em sua sistemática de denúncia.

\section{A PERSPECTIVA DAS REPÚBLICAS BOLIVARIANAS:} SAINDO DO SISTEMA INTERNACIONAL DE PROTEÇÃO DE INVESTIMENTOS?

Esta seção se dedica a entender a motivação e a estratégia das repúblicas bolivarianas ao decidirem por denunciar a Convenção de Washington de 1965 como medida de saída do sistema internacional de proteção de investimentos.

Antes de passarmos a esta análise, no entanto, é importante esclarecermos o contexto nos quais estes países estão inseridos, que é aquele da Aliança Bolivariana para os Povos da Nossa América (“ALBA”). A ALBA é um tratado de cooperação, criado em 2004 por Venezuela e Cuba, e que se baseia na ideia de integração social, política e econômica, como uma alternativa ao modelo de integração regional neoliberal.

O objetivo da ALBA, portanto, não se restringe à liberalização comercial, mas também envolve a promoção e proteção de direitos sociais, tendo como fundamento a ideia de solidariedade e complementariedade entre países. A ALBA hoje conta com mais de 12 Estados membros e ainda 3 Estados observadores.

Em 2007, esse movimento de reação ao ICSID começa a se desenvolver de forma mais acintosa, quando Bolívia, Venezuela e Nicarágua declaram sua intenção de se retirar do Fundo Monetário Internacional, do Banco Mundial e do ICSID. ${ }^{5} \mathrm{~A}$ justificativa era, em suma, o interesse em garantir o direito de regular investimento estrangeiro em seu próprio território, servindo esta medida como rejeição à pressão diplomática e da mídia exercida por multinacionais, que tenham resistido à aplicação de regras soberanas pela mera ameaça de iniciar um procedimento arbitral contra os Estados recebedores do investimento. ${ }^{6}$

5 Gaillard, Emmanuel, "The denunciation of the ICSID Convention”, New York Law Journal, vol. 237, no. 122, terça feira 26 de junho de 2007.

6 Comitê para a abolição da Dívida do Terceiro Mundo, "Bolivia, Venezuela and Nicaragua withdraw together from the ICSID”, 2 de maio de 2007, disponível em: http://cadtm.org/ Bolivia-Venezuela-and-Nicaragua (ultimo acesso: 03 de fevereiro de 2015). 
Esta revista forma parte del acervo de la Biblioteca Jurídica Virtual del Instituto de Investigaciones Jurídicas de la UNAM

No contexto da América Latina, portanto, apesar da noção de sistema de proteção internacional de investimento estrangeiro abranger também os tratados de proteção material do investimento (bi ou multilaterais), os Estados das chamadas Repúblicas Bolivarianas veem na arbitragem de investimento sob os auspícios do ICSID uma grande ameaça à sua soberania.

Com efeito, em termos discursivos, a percepção do Direito internacional do investimento estrangeiro como um sistema único, dotado de fontes materiais estabelecidas nos diversos acordos internacionais de investimentos existentes e uma estrutura de aplicação de tais normas consolidada, principalmente, no ICSID, ${ }^{7}$ leva ao inevitável amálgama entre ambos aspectos, para prejuízo da análise racional e da clareza. Há, porém, um aspecto contraditório em tal discurso: se os acordos são feitos para favorecer os investidores, eventuais arbitragens que, aplicando suas normas, lhes deem ganho não são enviesadas; apenas aplicam regras negociadas e aceitas entre Estados.

Se, integrado, o sistema internacional de proteção de investimentos estrangeiros efetivamente tende a restringir o espaço de implementação de políticas públicas, ${ }^{8}$ tal culpa não pode recair sobre os ombros da arbitragem. Tanto do ponto de vista da qualidade técnica das decisões, quanto da efetividade dos instrumentos para evitar a eventual parcialidade dos árbitros, parece mais razoável colocar a culpa nas regras materiais, não na composição dos tribunais e, muito menos, pela vinculação do ICSID com o Grupo Banco Mundial. ${ }^{9}$

Não obstante, essa percepção da arbitragem como bem menos parcial que os tratados com regras materiais sobre investimentos parece não haver conquistado as convicções bolivarianas. Para uma análise mais detalhada, nas subseções seguintes abordaremos detidamente as perspectivas bolivia-

7 Costa, José A. F. Direito internacional do investimento estrangeiro, Curitiba, Juruá, 2011.

8 Harten, Gus van, Investment Treaty Arbitration and Public Law, Oxford, Oxford University Press, 2007; Harten, Gus van; Loughlin, Martin, Investment Treaty Arbitration as a Apecies of Global Administrative Law, European Journal of International Law, Florença, European University Institute, 2006, v. 17, n. 1.

9 Costa, José A. F., "Brasil e arbitragem internacional de investimentos: realidade e possibilidades”, in Rosado de Sá Ribeiro, Marilda (org.), Direito Internacional dos Investimentos, Rio de Janeiro, Renovar, 2014, v. 1, pp. 247-270; Costa, José A. F., “Tentações, reputação e cultura: imparcialidade na arbitragem entre investidores e Estados”, Revista de Arbitragem e Mediação, v. 21, 2009, pp. 30-63. 
Esta revista forma parte del acervo de la Biblioteca Jurídica Virtual del Instituto de Investigaciones Jurídicas de la UNAM www.juridicas.unam.mx

na, venezuelana e equatoriana para propor uma reflexão sobre a efetividade da denúncia da Convenção de Washington dentro deste objetivo de "se retirar do sistema de proteção de investimento”.

\section{A perspectiva da Bolívia}

A Bolívia foi o primeiro país a implementar esta estratégia da ALBA e notificou ao ICSID sua decisão de denunciar a Convenção de Washington em 2 de maio de $2007 .{ }^{10}$ Em sua motivação, o governo boliviano indica os problemas que, em sua visão, afetavam o sistema de arbitragem investidor-Estado. Os principais problemas são (i) uma aparente tendência pró investidor, (ii) falta de transparência; (iii) falta de um mecanismo de apelação; (iv) altos custos de transação, e; (v) pedidos de indenização irracionais. ${ }^{11}$

Em particular, o caso Aguas del Tunari v. Republica da Bolivia foi mencionado pelo governo boliviano como um exemplo ilustrativo de todos os problemas que motivaram o Estado a denunciar a Convenção de Washington.

Desde este episódio, em 2007, a Bolívia fez diversos anúncios públicos de que iria terminar ou denunciar seus tratados bilaterais de proteção de investimento. Em 2009, isto passou a ser um objetivo constitucional. ${ }^{12}$ Os tratados assinados pela Bolívia que continham uma disposição acerca de investimentos (como o Tratado de Livre Comércio com o México ou o Tratado Bilateral de Investimento com os Estados Unidos) foram denunciados

10 De acordo com o previsto no artigo 71 da Convenção de Washington, a denúncia passa a ser efetiva após 6 meses, de forma que a partir de 3 de novembro de 2007, a Convenção não estava mais em vigor para a Bolívia.

11 Arismendi, Elizabeth, La experiencia del Estado plurinacional de Bolivia em el Centro de Arreglos de Diferencias Relativas Ainversiones (CIADI). Disponível em: http://www.ohadac.com/ telechargement/bibliographie/10/0/experiencia-boliviana-en-el-ciadi-en-el-centro-de-arreglos-de-diferencias-relativas-a-inversiones.arismendi-elizabeth.pdf (último acesso em 03 de fevereiro de 2015).

12 O artigo 9 das disposições transitórias da Constituição da Bolívia indica que "Los tratados internacionales anteriores a la Constitución y que no la contradigan se mantendrán en el ordenamento jurídico interno, con rango de ley. En el plazo de cuatro años desde la elección del nuevo Órgano Ejecutivo, éste denunciará y, en su caso, renegociará los tratados internacionales que sean contrarios a la Constitución”. 
Esta revista forma parte del acervo de la Biblioteca Jurídica Virtual del Instituto de Investigaciones Jurídicas de la UNAM

ou renegociados com o objetivo de não conter disposições relacionadas a investimento estrangeiro. ${ }^{13}$

A própria constituição boliviana assume uma posição bastante contrária ao investimento estrangeiro ao estipular que o investimento nacional será priorizado em detrimento do estrangeiro (art. 320) e indicando que o Estado Plurinacional da Bolívia é independente em todas as decisões de política pública interna e não se sujeitará a condições ou imposições de Estados, bancos ou instituições financeiras bolivianas, estrangeiras, multilaterais ou mesmo de empresas transnacionais.

É curioso pontuar que o número de arbitragens de investimento contra a Bolívia no âmbito do ICSID é similar ao número de arbitragens ad hoc (Regulamento da UNCITRAL) ao qual ela se sujeitou. ${ }^{14}$ Também se pode destacar que não há informação pública disponível sobre condenações da Bolívia em casos de arbitragem de investimento, que possam explicar sua opção por denunciar a Convenção de Washington, saindo do sistema ICSID, mas mantendo-se vinculada a outras formas de arbitragem de investimento previstas nos tratados bilaterais de investimento ainda em vigor. ${ }^{15}$

\section{A perspectiva do Equador}

O Equador, diferentemente da Bolívia, primeiramente adotou a estratégia de restringir a jurisdição do ICSID. Em 4 de dezembro de 2007, o Secretário Geral do ICSID recebeu a notificação de que o Equador excluiria da jurisdição do ICSID futuras disputas relacionadas a petróleo, gás e mineração, nos termos do art. 25(4) da Convenção de Washington.

13 Segundo a UNCTAD, a Bolívia tem hoje, em vigor, 15 tratados bilaterais de proteção de investimento. A lista completa e atualizada pode ser acessada em: http://investmentpolicyhub. unctad.org/IIA/CountryBits/24\#iiaInnerMenu (último acesso em 03 de fevereiro de 2015).

14 A Bolívia participou de 4 (quatro) casos no âmbito do ICSID (dois deles ainda pendentes (Pan American Energy LLC v. Plurinational State of Bolivia e Quiborax S.A. and Non-Metallic Minerals S.A. v. Plurinational State of Bolivia). Além destes, a Bolívia já participou de pelos menos cinco casos de investimento, alguns ad hoc administrados pela Corte Permanente de Arbitragem, outros submetidos às regras da Câmara de Comércio de Estocolmo.

15 Lazo, R. Polanco, Is there a Life for Latin American Countries After Denouncing the ICSID Convention? Disponível em: http: / / www.transnational-dispute-management.com/article. asp?key=2037 (último acesso em 3 de fevereiro de 2015). 
Esta revista forma parte del acervo de la Biblioteca Jurídica Virtual del Instituto de Investigaciones Jurídicas de la UNAM www.juridicas.unam. $\mathrm{mx}$

O efeito desta notificação, no entanto, é limitado. Isto porque, o efeito legal de tal notificação apenas opera para casos em que o Estado não tivesse consentido previamente para este tipo de disputa. ${ }^{16}$ No caso do Equador, no entanto, o Estado havia consentido genericamente em submeter disputas ao ICSID em diversos setores econômicos, por meio dos tratados de proteção de investimento em vigor. ${ }^{17}$

Diante do alcance limitado de sua estratégia, em 6 de julho de 2009, o Equador denunciou a Convenção de Washington, tendo esta se tornado efetiva em 7 de Janeiro de 2010.

Dentro desta estratégia de gradualmente sair do sistema ICSID, o Equador também encerrou diversos tratados bilaterais de proteção de investimento. Em 2008, o Equador denunciou seus tratados bilaterais com Cuba, República Dominicana, El Salvador, Guatemala, Honduras, Nicarágua, Paraguai, Romênia e Uruguai. A partir de 2010, a Corte Constitucional do Equador declarou diversos BIT's inconstitucionais, embasando as denúncias no direito nacional. ${ }^{18}$

A questão fundamental na perspectiva da corte constitucional não é a proibição ao investimento estrangeiro per se, mas a limitação à concessão de sua jurisdição soberana a instituições arbitrais internacionais em disputas relacionadas a contratos ou comércio entre o Estado e pessoas naturais ou jurídicas, o que é proibido pelo art. 422 da Constituição Equatoriana. ${ }^{19}$

16 UNCTAD Denunciation of the ICSID Convention and BITS: Impact on Investor-State Claims, IIA Issues note n. 2, december 2010, p. 4.

17 Esta questão se tornou controversa em dois casos: Murphy Exploration and Production Company International v. Republic of Ecuador (iniciado em 15 de Abril de 2008) e Repsol YPF Ecuador and others v. Republic of Ecuador e PetroEcuador (iniciado em 08 de Agosto de 2008). Este segundo caso foi encerrado antes de ter uma decisão sobre a questão de jurisdição, no entanto, no primeiro caso, em obter dictum, o Tribunal Arbitral rejeitou a objeção do Equador à jurisdição do ICSID com base na notificação do art. 25(4) da Convenção de Washington. No caso Murphy Exploration and Production Company International v. Republic of Ecuador, o Tribunal Arbitral aceitou, no entanto, a objeção à jurisdição baseada no descumprimento do período de seis meses para consultas e negociação, previsto no artigo VI do Acordo Bilateral entre Estados Unidos e Equador.

18 Os acordos afetados por estas decisões foram os celebrados com França, Canada, Finlândia, China, Chile, Suécia, Países Baixos, Suíça, Venezuela, Estados Unidos, Reino Unido - Irlanda, Alemanha, Argentina, Espanha, Peru, Itália e Bolívia.

19 Existem disposições na constituição do Equador que mencionam e, de certa forma, condicionam a presença de investimento estrangeiro no Equador. Ele é estimulado, juntamente com o investimento doméstico, e tido como tendo um papel de suplementar o investimento 
Esta revista forma parte del acervo de la Biblioteca Jurídica Virtual del Instituto de Investigaciones Jurídicas de la UNAM

Após estas decisões no âmbito da Corte Constitucional, o governo do Equador iniciou o processo interno para denúncia de todos seus tratados bilaterais remanescentes, o que foi aprovado pela Assembleia Nacional. Atualmente, segundo a UNCTAD, o Equador possui 16 BITs em vigor. ${ }^{20}$

Historicamente, o Equador é um dos países com maior número de casos públicos contra si. Atualmente, o Equador possui 3 casos em trâmite contra si e 10 concluídos no âmbito do ICSID. Dos casos concluídos, o Equador obteve êxito em 3 deles, tendo realizado transações em outros 5 e sido condenado a pagar compensação monetária em outros 2. Além disso, o Equador responde, atualmente, a outros 7 casos arbitrais sob o Regulamento da UNCITRAL. ${ }^{21}$ Dos casos conhecidos fora do âmbito do ICSID, o Equador prevaleceu em 2, tendo sido condenado a pagar uma compensação monetária em outros dois. ${ }^{22}$

De um ponto de vista exclusivamente de resultados, o Equador teve resultados melhores no sistema ICSID do que fora dele, o que talvez justi-

doméstico, desde que obedecendo ao previsto no ordenamento jurídico interno equatoriano. Neste sentido, o art. 339 da Constituição do Equador assim dispõe:

"Art. 339.- El Estado promoverá las inversiones nacionales y extranjeras, y establecerá regulaciones específicas de acuerdo a sus tipos, otorgando prioridad a la inversión nacional. Las inversiones se orientarán con criterios de diversificación productiva, innovación tecnológica, y generación de equilibrios regionales y sectoriales.

La inversión extranjera directa será complementaria a la nacional, estará sujeta a un estricto respeto del marco jurídico y de las regulaciones nacionales, a la aplicación de los derechos y se orientará según las necesidades y prioridades definidas en el Plan Nacional de Desarrollo, así como en los diversos planes de desarrollo de los gobiernos autónomos descentralizados" (grifos nossos).

20 Os acordos em vigor são com Argentina, Bolívia, Canada, Chile, China, França, Alemanha, Itália, Países Baixos, Peru, Espanha, Suécia, Suíça, Reino Unido, Estados Unidos e Venezuela. Informação disponível em: http://investmentpolicyhub.unctad.org/IIA/ CountryBits /61\#iiaInnerMenu (último acesso em 08 de fevereiro de 2015).

21 Os casos de condenação do Equador neste âmbito são famosos. Tratam-se do caso Chevron e Texaco v. Equador, no qual o Equador foi condenado a pagar USD 96,355,639.17 em danos às empresas e o caso Occidental Exploration and Production Company v. Equador, no qual o Equador foi condenado a pagar compensação no valor total de USD 71,533,649, além de juros.

22 LAZO, R. Polanco. Is there a life for latin American countries after denouncing the ICSID Convention? Disponível em: http://www.transnational-dispute-management.com/article. asp?key=2037 (último acesso em 03 de fevereiro de 2015). 
Esta revista forma parte del acervo de la Biblioteca Jurídica Virtual del Instituto de Investigaciones Jurídicas de la UNAM www.juridicas.unam.mx

ficasse o movimento de encerrar também os tratados bilaterais de investimento e não apenas denunciar a Convenção de Washington. ${ }^{23}$

\section{A perspectiva da Venezuela}

Seguindo a estratégia de Bolívia e Equador, em 24 de janeiro de 2012, a Venezuela denunciou a Convenção de Washington, retirando-se do sistema ICSID em 25 de julho de 2012.

Em sua notificação de denúncia, a Venezuela argumentou que sua adesão ao sistema, datada de 1993, foi realizada por um governo "fraco e sem legitimidade popular, pressionado por interesses econômicos transnacionais envolvidos no desmantelamento da soberania nacional da Venezuela”. Além disso, indicou o governo que considerava a Convenção de Washington como contrária à sua constituição de 1999, que proíbe o uso de “jurisdição internacional" em contratos de interesse público. ${ }^{24}$

Não há nenhuma previsão que, como no caso da Bolívia, priorize o investimento nacional, ou que, como no caso do Equador, preveja-o como suplementar ao doméstico. Pelo contrário, a previsão é a de tratamento isonômico ao investimento nacional, tendo-se como implícita a cláusula de eleição de foro nacional, sujeito ao direito nacional, nos casos de contratos tidos como de interesse público. ${ }^{25}$

23 A condenação do Equador no caso Oxy v. Equador, datada de 5 de outubro de 2012, no valor de USD 1,77 bilhões, além de juros, talvez justifique a posição anti-ICSID do Equador. O caso, no entanto, contou com um voto vencido e está, atualmente, em fase de anulação perante um comitê ad hoc.

24 Notas ALBA-TCP. Gobierno Bolivariano denuncia convenio com Ciadi. Caracas, Venezuela, 25 de janeiro de 2012. Disponível em: http: / / alba-tcp.org/contenido/gobierno-bolivariano-denuncia-convenio-con-ciadi-25-de-enero-de-2012 (último acesso em 09 de janeiro de 2015).

25 É esta a disposição do art. 151 da Constituição de 1999 da República Bolivariana da Venezuela: "Artículo 151. En los contratos de interés público, si no fuere improcedente de acuerdo con la naturaleza de los mismos, se considerará incorporada, aun cuando no estuviere expresa, una cláusula según la cual las dudas y controversias que puedan suscitarse sobre dichos contratos y que no llegaren a ser resueltas amigablemente por las partes contratantes, serán decididas por los tribunales competentes de la República, de conformidad con sus leyes, sin que por ningún motivo ni causa puedan dar origen a reclamaciones extranjeras" (grifos nossos). 
Esta revista forma parte del acervo de la Biblioteca Jurídica Virtual del Instituto de Investigaciones Jurídicas de la UNAM

A estratégia da Venezuela com relação à sua saída do sistema internacional de proteção ao investimento parece também se restringir ao ICSID. ${ }^{26} \mathrm{O}$ Estado não buscou encerrar os outros tratados bilaterais de investimento, tendo, na verdade, a partir de 2008, negociado e ratificado tratados bilaterais de proteção de investimento com a Bielorrússia, Rússia e o Vietnam. Nenhum destes novos tratados, no entanto, contém uma cláusula de resolução de conflito investidor-Estado prevendo arbitragem ICSID. Atualmente, a Venezuela possui 27 tratados bilaterais de proteção de investimento em vigor. ${ }^{27}$

A Venezuela é o segundo Estado mais demandado no ICSID, atrás apenas da Argentina. Em 2012, segundo a UNCTAD, havia 11 casos concluídos no âmbito do ICSID (4 casos tendo sido dispensados, 4 casos encerrados pelo investidor, 1 caso encerrado por acordo e 2 condenações contra o Estado). Nesta mesma data, havia ainda 26 casos pendentes no âmbito do ICSID, 9 dos quais foram iniciados após a notificação de denúncia da Convenção de Washington pela Venezuela. ${ }^{28}$

Diferentemente dos casos da Bolívia e do Equador, a maior parte dos casos conhecidos de arbitragem de investimento contra a Venezuela se deram no âmbito do ICSID. Este fato talvez possa explicar a reação contra o ICSID e o sistema que ele representa.

\section{ALTERNATIVAS AO ICSID PARA REPÚBLICAS BOLIVARIANAS}

Como visto nas seções anteriores, Bolívia, Equador e Venezuela adotaram estratégias diferentes para se retirar do sistema internacional de proteção de investimento. Todos estes Estados, no entanto, optaram por denunciar

26 Em 2008, antes, portanto, de denunciar a Convenção de Washington, a Venezuela notificou os Países Baixos de seu interesse em denunciar o BIT que entrou em vigor em 1993, evitando sua renovação por um período adicional de 10 anos.

27 A Venezuela possui tratados em vigor com: Argentina, Barbados, Bielorrúsia, União Econômica Bélgica-Luxemburgo, Canada, Chile, Costa Rica, Cuba, República Tcheca, Dinamarca, Equador, França, Alemanha, Indonésia, Irã, Itália, Lituânia, Paraguai, Peru, Portugal, Rússia, Espanha, Suécia, Suíça, Reino Unido, Uruguai e Vietnã. Informação disponível em: http: / / investmentpolicyhub.unctad.org/IIA / CountryBits /228\#iiaInnerMenu (último acesso em 08 de fevereiro de 2015).

28 Apesar do grande volume de casos conhecidos, até 2012, apenas 2 casos haviam sido definitivamente sentenciados contra a Venezuela. 
Esta revista forma parte del acervo de la Biblioteca Jurídica Virtual del Instituto de Investigaciones Jurídicas de la UNAM

a Convenção de Washington como medida máxima representativa de seu desacordo com o que estava à sua disposição no que diz respeito à proteção internacional dos investimentos.

Isto não significa, no entanto, que estes Estados sejam completamente avessos ao investimento estrangeiro ou mesmo que não reconheçam sua importância ao desenvolvimento nacional. Ao menos em uma perspectiva constitucional, a Bolívia prioriza o investimento nacional, mas não proíbe ou veda o estrangeiro; o Equador prevê o investimento estrangeiro como suplementar ao nacional, e; a Venezuela equipara-o ao nacional.

Em outras palavras, na busca de um "inimigo comum", parece-nos que estes Estados não o reconhecem no capital estrangeiro ou mesmo nas regras substantivas dos tratados de proteção de investimento, mas em se sujeitar a órgãos jurisdicionais internacionais de resolução de conflitos e, particularmente, ao ICSID. As alternativas que têm sido discutidas pela Bolívia, o Equador e a Venezuela nos indicam a adoção desta posição.

A alternativa natural que existe ao ICSID e a qualquer forma alternativa de resolução de conflitos relacionados a investimentos é a utilização de cortes domésticas no Estado hospedeiro. Existem estratégias diferentes a serem adotadas, conforme veremos na seção seguinte para os casos da Bolívia, Equador e Venezuela.

\section{Avaliação das Opções de Bolívia, Equador eVenezuela}

No caso da Bolívia, a constituição reconheceu no artigo 320, ${ }^{29}$ que os investimentos estrangeiros estão sujeitos à jurisdição, leis e às autoridades bolivianas, com renúncia expressa a qualquer tipo de proteção diplomática. Em linha com este conceito, mas mais especificamente na questão ligada aos hidrocarbonetos, o art. 366 da constituição ${ }^{30}$ proibiu o recurso

29 O artigo 320, II prevê que “toda inversión extranjera estará sometida a la jurisdicción, a las leyes y a las autoridades bolivianas, y nadie podrá invocar situación de excepción, ni apelar a reclamaciones diplomáticas para obtener un tratamiento más favorable" (grifos nossos).

30 O artigo 366 prevê que: “Todas las empresas extranjeras que realicen actividades en la cadena productiva hidrocarburífera en nombre y representación del Estado estarán sometidas a la soberanía del Estado, a la dependencia de las leyes y de las autoridades del Estado. No se reconocerá en ningún caso tribunal ni jurisdicción extranjera y no podrán 
Esta revista forma parte del acervo de la Biblioteca Jurídica Virtual del Instituto de Investigaciones Jurídicas de la UNAM

a cortes ou jurisdições estrangeiras e também estabeleceu uma proibição aos investidores de se utilizarem de arbitragem internacional ou proteção diplomática. ${ }^{31}$

Por outro lado, existem autorizativos legais, anteriores à constituição de 1999, como é o caso da Lei Boliviana de Arbitragem e também regulamentação contratual, que autorizam empresas públicas bolivianas a participarem de arbitragens, inclusive internacionais, para contratos de compra e venda de mercadorias. Isto é, diante da forte linguagem utilizada na constituição boliviana, em especial em seus artigos 320 e 366, o caso boliviano gera dúvidas com relação à verdadeira preocupação do Estado: se com qualquer tipo de arbitragem ou apenas com o caso de arbitragens do tipo investidor-Estado fundadas em tratados internacionais de proteção de investimento.

Em princípio, parece-nos que estes autorizativos infraconstitucionais não teriam sido recepcionados pela constituição de 1999, de forma que diante da ordem constitucional boliviana, a utilização de qualquer tipo de arbitragem internacional (ou sujeição do Estado ou empresas públicas) ao direito estrangeiro ou a uma jurisdição internacional, seria proibida.

O caso do Equador é ligeiramente parecido com o Boliviano. Em princípio, como vimos, há uma proibição expressa de que o Estado entregue sua jurisdição a entidades internacionais de arbitragem em disputas na modalidade investidor-Estado. ${ }^{32}$ Entretanto, o parágrafo segundo deste mesmo

invocar situación excepcional alguna de arbitraje internacional, ni recurrir a reclamaciones diplomáticas" (grifos nossos).

31 Apesar da regulamentação bastante estrita no que tange ao mercado de hidrocarbonetos, há permissivo legal para que a YPFB (Yacimientos Petroliferos Fiscales Bolivianos) se sujeite ao direito estrangeiro e à arbitragem internacional quando da compra internacional de mercadorias ou serviços de companhias sem sede na Bolívia, quando estes bens ou serviços não estiverem disponíveis no mercado doméstico ou for de benefício à YPFB.

32 A proibição de recurso a entidades internacionais de arbitragem está prevista no artigo 422 da Constituição do Equador:

"Art. 422.- No se podrá celebrar tratados o instrumentos internacionales en los que el Estado ecuatoriano ceda jurisdicción soberana a instancias de arbitraje internacional, en controversias contractuales o de índole comercial, entre el Estado y personas naturales o jurídicas privadas.

Se exceptúan los tratados e instrumentos internacionales que establezcan la solución de controversias entre Estados y ciudadanos en Latinoamérica por instancias arbitrales regionales o por órganos jurisdiccionales de designación de 
Esta revista forma parte del acervo de la Biblioteca Jurídica Virtual del Instituto de Investigaciones Jurídicas de la UNAM

artigo permite uma exceção para o caso de disputas envolvendo cidadãos da América Latina por entidades regionais de arbitragem ou para entidades judicantes designadas pelos países signatários do tratado.

A proibição do artigo 422 da Constituição, no entanto, não compreende arbitragens investidor-Estado estipuladas contratualmente. Este entendimento é também corroborado pelo Código Orgânico de Produção, Comércio e Investimento, que, no artigo 27, expressamente prevê a solução de disputas entre investidores e o Estado por meio de arbitragem. Há, inclusive relatos de que o Equador celebrou oito contratos de proteção de investimento com investidores Chineses e Europeus contendo cláusulas arbitrais, conforme previstas no Código Orgânico de Produção, Comércio e Investimento. ${ }^{33}$

A Venezuela adotou uma abordagem similar à do Equador. O artigo 151 da constituição venezuelana dispõe que as cortes domésticas terão jurisdição exclusiva em disputas de investimento estrangeiro quando houver interesse público nos contratos. Não haveria, portanto, uma proibição genérica ao uso da arbitragem de investimento, que pudesse ser considerada uma questão de política pública geral. A Corte Constitucional Suprema da Venezuela já decidiu que contratos de interesse público são aqueles que são celebrados pelos órgãos competentes da República e:

cujo objeto seja crucial ou essencial para atingir os objetivos e tarefas do Estado venezuelano buscando satisfazer interesses individuais ou coincidentes da comunidade nacional e não apenas aqueles de um setor particular, como nos casos de contratos de interesse do estado ou local, quando o objeto de tais atos são críticos ou essenciais para os habitantes daquele estado ou entidade local... ${ }^{34}$

los países signatarios. No podrán intervenir jueces de los Estados que como tales o sus nacionales sean parte de la controversia.

En el caso de controversias relacionadas con la deuda externa, el Estado ecuatoriano promoverá soluciones arbitrales en función del origen de la deuda y con sujeción a los principios de transparencia, equidad y justicia internacional" (grifos nossos).

33 Rodrigo Jijón-Letort, Juan Manuel Marchán, "National and International Arbitration in Ecuador", The Arbitration Review of the Americas 2014, Section 3: Country Chapters: Ecuador, disponível em:

http: / / globalarbitrationreview.com/reviews/57/sections/197/chapters/2264/ecuador/ (último acesso em 13 de fevereiro de 2015).

34 Tribunal Supremo de Justicia de Venezuela, Julgamento de 24 de Setembro de 2002,no caso Andrés Velásquez, Elías Mata and Enrique Márquez, disponível em: http: / / www.tsj.gov.ve/ 
Há, portanto, um reconhecimento da alta instância judicial Venezuelana de que a arbitragem pode ser utilizada em determinadas circunstâncias, desde que os contratos não sejam de interesse público. Em outras palavras, em contratos de interesse genérico, ainda que celebrados com o Estado, é aceitável a utilização de arbitragens internacionais na modalidade investidor-Estado.

Na prática, no entanto, nos parece difícil pensar em algum caso, em que um contrato de investimento, celebrado com o Estado seria compreendido por este conceito flexível de "interesse genérico" e não de "interesse público". Como bem se sabe, uma das características marcantes dos casos de investimento é sua íntima relação com projetos de infraestrutura ou de exploração de recursos naturais, intimamente ligados ao desenvolvimento nacional e à exploração de recursos naturais e, nestes termos, ao interesse público.

\section{A criação de um organismo regional de arbitragem}

Uma das propôs tas da ALBA, como alternativa ao sistema ICSID, é a criação de um centro regional de resolução de disputas relacionadas a investimentos. A linha mestra estabelecida para este novo centro regional seria a de garantir a não interferência de multinacionais no desenvolvimento do interesse público e a supremacia das decisões nacionais sobre decisões de órgãos arbitrais.

A ALBA endossou a proposta de criação de um centro regional de arbitragem, como alternativa ao ICSID da União das Nações Sul Americanas - UNASUL. A proposta foi inicialmente discutida em 2009. A primeira proposta foi apresentada pelo grupo de trabalho em 2011 e oito conceitos centrais em resposta a diversas críticas das repúblicas bolivarianas ao sistema ICSID formam sua coluna vertebral. ${ }^{35}$

decisiones/scon/Septiembre/2241-240902-00-2874\%20.htm (último acesso em 13 de fevereiro de 2015).

35 Fiezzoni, Silvia Karina, "The challenge of UNASUR Member Countries to replace ICSID Arbitration”, Beijing Law Review, 2011, 2, pp. 134-144. Disponível em: http: / /www.SciRP. org/journal/blr (último acesso em 20 de fevereiro de 2015). A Autora indica que os elementos centrais da proposta da UNASUL são os que trazemos neste artigo. No entanto, não foi possível encontrar registros públicos de uma proposta oficial da UNASUL neste sentido. 
Esta revista forma parte del acervo de la Biblioteca Jurídica Virtual del Instituto de Investigaciones Jurídicas de la UNAM

O primeiro destes conceitos é o de jurisdição limitada. Em princípio, a regra geral seria a de excluir da jurisdição deste novo organismo questões relacionadas a saúde, impostos, energia, entre outros, salvo disposição expressa em sentido contrário. Questões relacionadas à legitimidade do direito nacional seriam excluídas por completo da jurisdição deste centro.

O segundo pilar do sistema proposto para este centro é o chamado princípio de exaustão dos remédios locais, que exige a exaustão de medidas judiciais e administrativas nacionais como pré-condição à arbitragem. $\mathrm{Na}$ proposta original não há um limite de tempo para que as medidas nacionais sejam finalizadas ou mesmo um conceito de "razoabilidade" para permitir o acesso à arbitragem após este lapso temporal.

Em consonância com o espírito de evitar o recurso à via arbitral, bem como com as propostas mais modernas da UNCTAD, o terceiro conceito é exigir que eventuais disputas sejam submetidas a consultas prévias ou mediação. Este período de negociação obrigatório entre as partes (chamado também de cooling off) pode ser importante para reduzir a litigiosidade típica destas disputas e também para incentivar acordos.

Em resposta à crítica frequente de viés pró-investidor na indicação dos árbitros que comporão o tribunal arbitral pelo Presidente do Banco Mundial (na falta de acordo entre as partes ou na falta de indicação de um árbitro por uma das partes), a proposta da UNASUL é a de que o Diretor Geral da organização sorteie o árbitro a ser designado. O fato de haver um sorteio dentre os nomes que compõem uma determinada lista, em substituição à escolha livre dentre estes mesmos nomes, neutralizaria, de certa forma, este viés pró-investidor do qual o ICSID é taxado. Além disso, a proposta a UNASUL compreende a elaboração de um código de conduta que incluiria, além do tradicional exame de independência e imparcialidade, a probabilidade de um árbitro ter um estado de espírito ou pré-julgamento em relação a qualquer das partes.

O quinto elemento inovador do sistema proposto pela UNASUL é a criação de um procedimento específico para a consolidação de dois ou mais procedimentos arbitrais envolvendo questões de fato ou de direito similares. O objetivo desta previsão, não existente no Regulamento UNCITRAL e no regulamento do ICSID, mas comum em outras câmaras arbitrais, como a da CCI, é evitar decisões e sentenças contraditórias em matérias que sejam semelhantes envolvendo as mesmas partes. 
Diferentemente do sistema de anulação previsto na Convenção de Washington, a proposta da UNASUL inclui um sistema de apelação. Este sistema consistiria no estabelecimento de um órgão permanente de apelação, que permitisse a revisão de questões de direito com base em um sistema de precedentes. O órgão seria composto por oito árbitros, três dos quais atuariam em cada caso concreto e o objetivo seria permitir a criação de uma jurisprudência coerente e consistente, em resposta às críticas frequentes que se faz ao sistema do ICSID.

Além disso, visando garantir publicidade e transparência, a proposta estabelece um dever geral de publicidade de documentos. Desta feita, arquivos, provas, audiências e sentenças, exceto para o que se relacionar à defesa e segurança do Estado e para os casos em que as partes estabeleçam confidencialidade de comum acordo.

Por fim, a oitava inovação proposta diz respeito ao reconhecimento e execução da sentença arbitral. De forma similar à Convenção de Washington, a sentença arbitral estaria sujeita à ratificação, revisão e anulação (havendo, como visto, a possibilidade de apelação), no entanto, após ela ser considerada final, ela seria auto executável de acordo com a Constituição e leis dos Estados signatários. Em termos práticos, não haveria uma diferença grande entre os requisitos previstos na Convenção de Nova Iorque de 1958. Isto é, diferentemente do previsto expressamente na Convenção de Washington, haveria a possibilidade de excepcionar o reconhecimento e execução da sentença arbitral por motivos de ordem pública..$^{36}$

Apesar de ser uma proposta inovadora do ponto de vista das alternativas para resolução de disputas relacionadas a investimentos, a proposta da criação de um centro regional como o proposto pela UNASUL é também passível de críticas.

A primeira delas pode ser direcionada ao escopo e alcance deste sistema, tanto de um ponto de vista geográfico quanto com relação às matérias a serem abrangidas no sistema. Do ponto de vista geográfico, diferentemente da proposta do ICSID, o Centro proposto nasce limitado à América Latina

36 É questionável se esta seria uma diferença significativa para a Convenção de Washington, já que o requisito de atendimento à ordem pública, conforme entendida na Convenção de Nova Iorque, pode ser encontrado nos diversos incisos que preveem a anulação da sentença arbitral na Convenção de Washington. 
Esta revista forma parte del acervo de la Biblioteca Jurídica Virtual del Instituto de Investigaciones Jurídicas de la UNAM

e, portanto, dificilmente será considerado um sistema mundial ou mesmo uma referência mundial.

Já do ponto de vista das matérias a serem submetidas à arbitragem, a proposta de excluir da jurisdição do centro questões relativas à saúde, impostos, energia e discussões relacionadas à legitimidade do direito nacional limita sobremaneira a atuação do Centro. $\mathrm{O}$ exame de conformidade das medidas adotadas localmente com parâmetros internacionais de proteção do investimento foi um dos pilares do desenvolvimento do direito internacional dos investimentos e é tido como um dos alicerces do sistema. Além disso, boa parte das disputas submetidas ao ICSID é relacionada, direta ou indiretamente, à saúde, energia e impostos. ${ }^{37}$

Além disso, por ser um sistema que nasce como uma resposta ao ICSID e seu suposto viés pró-investidor, o Centro poderia ser visto, inicialmente, como possuindo um viés pró-Estado. Além de não resolver a questão de imparcialidade, há um risco de amedrontar investidores ao sujeitar eventuais disputas do mesmo a este Centro38.

Também é discutível se esta proposta resolveria o problema central das repúblicas bolivarianas, conforme colocamos acima. Isto porque, segundo o que vimos, apenas o Equador possui uma disposição constitucional expressa que autoriza investidores latino americanos a iniciar arbitragens investidor-Estado contra o Estado Equatoriano, em um centro regional.

Por fim, de um ponto de vista técnico, apesar da proposta de exigir a exaustão dos remédios locais antes de submeter as disputas a um período de cooling off para consultas e, eventualmente, mediação, estar alinhada com o que é a recomendação da própria UNCTAD, a ausência de um critério de tempo razoável para ativar a cláusula arbitral pode gerar um sistema ainda mais moroso que o atual do ICSID. Haveria, portanto, um receio válido de que o centro se transformasse em algo inútil, de um ponto de vista prático, e que não resolvesse o problema de insegurança quanto à uma decisão final, tanto para o Estado quanto para o investidor.

37 Segundo R. Polanco Lazo, ao menos $12 \%$ das disputas registradas no âmbito do ICSID são relacionadas à energia elétrica ou outras formas de energia.

38 Este fator foi, inclusive, citado como fonte de receio do Uruguai nas discussões feitas no âmbito da UNASUL. 


\section{CONCLUSÃO: RUMOS EFETIVOS PARA A AMÉRICA LATINA?}

Como apresentado anteriormente, a Convenção de Washington representa a pedra angular do chamado sistema internacional de proteção de investimento. Historicamente, foi a partir da criação do ICSID que diversos tratados de proteção de investimento (bi e multilaterais) foram negociados e celebrados, seguindo o movimento de internacionalização do capital dos países desenvolvidos para países em desenvolvimento. A composição das regras procedimentais com as regras materiais estabelecidas por meio desses tratados é que compõe esse sistema internacional de proteção investimentos.

As repúblicas bolivarianas apresentadas neste artigo aderiram a esse sistema, em especial, na década de 90. Os tratados celebrados seguiam esse padrão internacional de estabelecer regras materiais e também o recurso a tribunais arbitrais internacionais (sejam no âmbito do ICSID, em outras instituições ou mesmo em arbitragens ad hoc). No entanto, como apresentamos, o desenrolar dos casos e algumas condenações marcantes contra elas geraram um movimento de crítica e de retirada do sistema, em especial a partir da segunda metade dos anos 2000.

Não se pode dizer, no entanto, que a resposta das repúblicas bolivarianas tenham sido coesas visando retirar-se do sistema como um todo, o que seria realizado mediante a denúncia tanto da Convenção de Washington, como dos tratados bi e multilaterais. O movimento unânime de Bolívia, Equador e Venezuela foi o de denunciar a Convenção de Washington, retirando seu consentimento à jurisdição do ICSID, e manter ou renegociar os acordos bilaterais de proteção ao investimento, inclusive com as previsões de recurso a arbitragens investidor-Estado.

A limitação à utilização do recurso à arbitragens investidor-Estado não se deu no âmbito internacional, mas no âmbito do direito interno, a nível constitucional. A Constituição da Bolívia proibiu o recurso a cortes estrangeiras e a arbitragens investidor-Estado de forma genérica. A Constituição do Equador seguiu linha parecida, excepcionando disputas envolvendo cidadãos da América Latina e entidades regionais. Por sua vez, a Constituição da Venezuela limitou o uso da arbitragem investidor-Estado a casos que não envolvam interesse público. 
Esta revista forma parte del acervo de la Biblioteca Jurídica Virtual del Instituto de Investigaciones Jurídicas de la UNAM

Há, portanto, um descompasso entre as obrigações assumidas internacionalmente por estes países e suas constituições. A opção de criação de um centro regional de resolução de disputas entre investidores e Estado, como aquele discutido no âmbito da UNASUL não nos parece ser uma alternativa efetiva para resolver este problema ou mesmo para constituir uma alternativa viável ao ICSID no âmbito mundial.

O escopo proposto, segundo os relatos de que se tem conhecimento, é limitado ao âmbito regional e, em termos de matérias, a questões que não se relacionem a saúde, impostos e energia. Há, ainda, o risco de que este centro surja com o estigma de protetor aos Estados, afugentando investidores e que não conte com o apoio de países importantes para a América Latina, como é o caso do Uruguai e do Brasil. ${ }^{39}$

Portanto, os rumos da América Latina com relação à proteção de investimento se mostram incertos. Se, por um lado, as Repúblicas Bolivarianas lideram o movimento de crítica ao sistema internacional de proteção de investimentos e, especialmente, ao ICSID, por outro, países como o Uruguai e Chile parecem ter receio de seguir esta linha e perder oportunidades de receber investimentos. Parece-nos, portanto, difícil, que se chegue a um consenso regional sobre a política e os mecanismos de proteção do investimento no âmbito da América Latina.

Retomando nossas três hipóteses iniciais, a análise dos casos em que Bolívia, Equador e Venezuela participaram não nos permite concluir que haja um viés arbitral contra os Estados, existiram decisões contrárias fortes contra esses países, mas também houve decisões favoráveis. Por outro lado, o movimento de denúncia da Convenção de Washington não acompanhado da denúncia de outros acordos internacionais de investimento nos permite ao menos refletir se há um efetivo questionamento aos acordos internacionais de investimento. Por fim, as proposições de que a denúncia da Convenção de Washington seria um mandamento constitucional, parece-nos um apoio retórico, de natureza muito mais política do que jurídica, conforme apresentamos na sessão anterior.

39 Apesar de o Brasil já ter assinados tratados bilaterais de proteção de investimento, nenhum destes tratados foi ratificado e chegou a entrar em vigor. Além disso, o Brasil não é signatário da Convenção de Washington e a posição mais recente do País no que diz respeito a este Centro Regional para a América Latina, é a de que o Brasil não assina tratados de proteção de investimento. 


\section{REFERÊNCIAS BIBLIOGRÁFICAS}

ARISMENDI, Elizabeth, La experiencia del Estado plurinacional de Bolivia em el Centro de Arreglos de Diferencias Relativas a Inversiones (CIADI). Disponível em: http://www.ohadac.com/telechargement/biblio graphie / 10/0/experiencia-boliviana-en-el-ciadi-en-el-centro-de-arreglos-dediferencias-relativas-a-inversiones. arismendi-elizabeth.pdf (último acesso em 03 de fevereiro de 2015).

Costa, José A. F., Direito internacional do investimento estrangeiro, Curitiba, Juruá, 2011.

, Brasil e arbitragem internacional de investimentos: realidade e possibilidades, in Rosado DE SÁ RIBEIRO, Marilda (org.), Direito Internacional dos Investimentos, Rio de Janeiro, Renovar, 2014, v. 1.

, "Tentações, reputação e cultura: imparcialidade na arbitragem entre investidores e Estados”, Revista de Arbitragem e Mediação, v. 21, 2009.

Dalmaso, Ricardo, Notes on the Persitent Latin American Countries' Attitude Towards Investment Arbitration and ICSID. Disponível em: http://kluwe rarbitrationblog.com/blog/2014/07/24/some-notes-on-the-latin-americancountries-attitude-towards-investment-arbitration-and-icsid/ (ultimo acesso em: 20 de fevereiro de 2015).

FIEZZONI, Silvia Karina, "The challenge of UNASUR Member Countries to replace ICSID Arbitration”, Beijing Law Review, 2011, 2. Disponível em: http://www.SciRP.org/journal/blr (último acesso em 20 de fevereiro de 2015).

Gaillard, Emmanuel, “The Denunciation of the ICSID Convention”, New York Law Journal, vol. 237, no. 122, terça feira 26 de junho de 2007. http: / / globalarbitrationreview.com/reviews/57/sections/197/chapters/2264 / ecuador/ (último acesso em 13 de fevereiro de 2015).

Harten, Gus van, Investment Treaty Arbitration and Public Law, Oxford, Oxford University Press, 2007.

Harten, Gus van e Loughlin, Martin, "Investment Treaty Arbitration as a Species of Global Administrative Law", European Journal of International Law, Florença, European University Institute, 2006, v. 17, n. 1.

Jijón-LeTORT, RODRIGO e MARChÁn, Juan Manuel, "National and International Arbitration in Ecuador", The Arbitration Review of the Americas, 2014, Section 3, Country Chapters, Ecuador. 
Esta revista forma parte del acervo de la Biblioteca Jurídica Virtual del Instituto de Investigaciones Jurídicas de la UNAM www.juridicas.unam. $\mathrm{mx}$

LAZO, R. Polanco, Is there a life for latin American countries after denouncing the ICSID Convention?, Disponível em: http://www.transnational-dispute-management.com/article.asp?key=2037 (último acesso em 03 de fevereiro de 2015).

Luís, Daniel Tavela, Proteção do investimento estrangeiro: o sistema do Centro Internacional para a Resolução de Disputas Relativas ao Investimento (CIRDI) e suas alternativas, FDUSP. dissertação de mestrado, São Paulo, 2013.

NOTAS ALBA-TCP, Gobierno Bolivariano denuncia convenio com CIADI. Caracas, Venezuela, 25 de janeiro de 2012. Disponível em: http: / / albatcp.org/contenido/gobierno-bolivariano-denuncia-convenio-con-ciadi-25-deenero-de-2012 (último acesso em 09 de janeiro de 2015)

PARRA, Antonio R., The History of ICSID, Oxford, Oxford University Press, 2012.

Tribunal Supremo de Justicia de Venezuela, Julgamento de 24 de Setembro de 2002, no caso Andrés Velásquez, Elías Mata and Enrique Márquez, disponível em: http://www.tsj.gov.ve/decisiones/scon/Septiembre/2241-240902-00-2874\%20.htm (último acesso em 13 de fevereiro de 2015).

UNCTAD Denunciation of the ICSID Convention and BITS: Impact on Investor-State Claims, IIA Issues Note n. 2, december 2010, p. 4.

W AIBEL, Michael et al., The Backlash Against Investment Arbitration: Perceptions and Reality, Kluwer Law International, 2010. 